\title{
Valor nutritivo e características fermentativas de silagens de capim-elefante com adição de casca de café
}

\section{Gleidson Giordano Pinto de Carvalho1, Rasmo Garcia ${ }^{2,5}$, Aureliano José Vieira Pires ${ }^{3,5}$, José Augusto Gomes Azevêdo ${ }^{4}$, Francisco Éden Paiva Fernandes ${ }^{1}$, Odilon Gomes Pereira ${ }^{2,5}$}

\author{
1 Doutorando em Zootecnia, UFV, Viçosa, MG. Bolsista do CNPq. \\ 2 DZO, UFV, Viçosa, MG. \\ ${ }^{3}$ DTRA/UESB - Itapetinga, BA. \\ ${ }^{4}$ Doutorando em Zootecnia, UFV, Viçosa, MG. Professor UESC, Ilhéus, BA. \\ ${ }^{5}$ Pesquisador do CNPq.
}

RESUMO - O experimento foi conduzido para avaliar a composição química, a digestibilidade in vitro da MS (DIVMS) e as características fermentativas de silagens de capim-elefante com diferentes níveis de casca de café. Utilizou-se o capimelefante contendo $17,2 \%$ de MS, cortado aos 45 dias de crescimento. Os níveis de adição foram de $0,6,12,18$ e $24 \%$ de casca de café, na base da matéria natural (peso/peso), com quatro repetições por tratamento. O material foi acondicionado em silos de PVC, adotando-se compactação de $500 \mathrm{~kg} / \mathrm{m}^{3}$. Observou-se aumento dos teores de MS, FDA, nitrogênio insolúvel em detergente ácido e lignina, em função dos níveis de casca de café. O teor de PB apresentou comportamento quadrático, estimando-se valor máximo de $9,9 \%$ de PB para o nível de $16,4 \%$ de adição de casca de café. Os valores de FDN reduziram linearmente e os teores de ácido lático das silagens comportaram-se de maneira quadrática em função dos níveis de casca de café, estimando-se valor máximo de $11,4 \%$ para o nível de $25,6 \%$ de casca. A casca de café foi eficiente em aumentar o teor de MS, mas diminuiu a DIVMS das silagens. A utilização de casca de café na ensilagem de capim-elefante melhorou as características fermentativas da silagem.

Palavras-chave: aditivo, ensilagem, fermentação, Pennisetum purpureum, subproduto

\section{Nutritive value and fermentation characteristics of elephantgrass silages with addition of coffee hulls}

\begin{abstract}
The experiment evaluated the chemical composition, in vitro DM digestibility (IVDMD), and fermentative characteristics of elephant grass silages with different coffee hull levels. The elephant grass presented $17.2 \%$ of dry matter (DM), cut with 45 days of growing. The coffee hull addition levels were $0,6,12,18$, and $24 \%$, in fresh matter basis (weight/weight) with four replications per treatment. The material was ensiled in cylindrical plastic silos. In the ensiling process, the forage packing density was $500 \mathrm{~kg} / \mathrm{m}^{3}$. It was observed increase of DM, acid detergent fiber, acid detergent insoluble nitrogen, and lignin concentration, as a function of coffee hull levels. Crude protein showed quadratic behaviour, estimating maximum CP value of $9.9 \%$ for the $16.4 \%$ coffee hull addition level. Neutral detergent fiber reduced linearly and silage lactic acid concentration showed quadratic behaviour as a function of coffee hull levels, estimating maximum value of $11.4 \%$ to $25.6 \%$ hull level. Coffee hull was efficient to increase silage DM concentration however, the silage IVDMD decreased. The coffee hulls use in elephantgrass ensilage improved the fermentative characteristics of the silage.
\end{abstract}

Key Words: additive, byproduct, ensilage, fermentation, Pennisetum purpureum

\section{Introdução}

A dificuldade de produzir alimentos de boa qualidade em determinadas localidades e épocas do ano é o principal motivo que impulsiona os produtores em geral a produzirem silagem.

Entre as forrageiras tropicais com potencial para produção de silagem, o capim-elefante destaca-se por sua elevada produção de MS (mais de 80 toneladas MS/ha/ ano). Entretanto, no momento ideal para ensilagem, quando o capim apresenta elevado valor nutritivo, que ocorre por volta dos 50 a 70 dias de crescimento após o corte de uniformização, normalmente o teor de umidade é elevado (Vilela, 1990)

O baixo teor de MS das forrageiras é um dos principais fatores responsáveis pela produção de silagem de baixo 
valor nutritivo. De acordo com Evangelista et al. (2004), para a produção de silagem de boa qualidade, a forrageira a ser ensilada deve apresentar teor de MS acima de $20 \%$. Como o capim-elefante no momento ideal de corte apresenta teor de MS de 15 a $20 \%$, estudos envolvendo a adição de materiais com elevado teor de MS na ensilagem têm sido conduzidos (Ferrari Jr. \& Lavezzo, 2001; Carvalho, 2006).

A diversidade de subprodutos e resíduos agroindustriais com potencial de utilização na alimentação de ruminantes é ampla em todo o País. Ferrari Jr. \& Lavezzo (2001), estudando a adição de farelo de mandioca na ensilagem de capimelefante, observaram aumento do teor de MS, com conseqüente melhoria na qualidade no material.

A casca de café, resíduo proveniente do beneficiamento do grão de café, apresenta elevado teor de MS e propriedades higroscópicas (Bernardino et al., 2005). Deste modo, se adicionada ao capim-elefante, poderá atuar como absorvente de umidade e favorecer a produção de silagem com boas características químicas.

O elevado teor de carboidratos solúveis da casca de café (26\%) (Souza et al., 2003) poderá ainda favorecer a fermentação, uma vez que esses carboidratos são essenciais para a rápida redução do $\mathrm{pH}$. Bons resultados têm sido encontrados em pesquisas envolvendo a adição de casca de café durante a ensilagem (Souza et al., 2003; Bernardino et al., 2005). Entretanto, nesses estudos não foram avaliadas as características fermentativas da silagem, como os teores de ácidos lático, acético e butírico.

O experimento foi conduzido com o objetivo de avaliar a composição química, a digestibilidade in vitro da MS e as características fermentativas de silagens de capimelefante com diferentes níveis de casca de café.

\section{Material e Métodos}

Utilizou-se o capim-elefante (Pennisetum purpureum, Schum.) proveniente de uma capineira preestabelecida, pertencente à Universidade Federal de Viçosa, Viçosa, MG.

O capim foi submetido ao corte de uniformização com altura média de $10 \mathrm{~cm}$ do solo e, após 45 dias de rebrota, com $17,2 \%$ de MS, foi colhido manualmente, picado em fragmentos de $2 \mathrm{~cm}$ em ensiladeira estacionária e ensilado conforme cinco tratamentos: níveis de casca de café de $0,6,12,18$ e $24 \%$, com base na matéria natural, previamente processada em moinho com peneira de malha de $2 \mathrm{~mm}$.

O delineamento experimental adotado foi o inteiramente casualizado, com cinco tratamentos e quatro repetições.

Antes de iniciar o processo ensilagem, amostras do capim-elefante e da casca de café foram colhidas para análises. A composição química do capim-elefante e da casca de café (Tabela 1) foi obtida segundo as metodologias descritas em Silva \& Queiroz (2002).

O material foi ensilado em silos experimentais de PVC, cilíndricos, com $0,15 \mathrm{~m}$ de diâmetro e $0,5 \mathrm{~m}$ de comprimento, adotando-se compactação de $500 \mathrm{~kg} / \mathrm{m}^{3}$. Os silos foram vedados e armazenados em galpão coberto durante 60 dias.

Após abertura dos silos, parte das amostras foi acondicionada em sacos de papel, mantida em estufa de présecagem (durante 72 horas a $65^{\circ} \mathrm{C}$ ) e triturada em moinho tipo Willey com peneira de malha de $1 \mathrm{~mm}$. As amostras foram submetidas às análises de nitrogênio total (NT), FDN, FDA, celulose, lignina, nitrogênio insolúvel em detergente ácido (NIDA), carboidratos solúveis (CHOs) e digestibilidade in vitro da MS (DIVMS), segundo metodologias descritas por Silva \& Queiroz (2002).

Parte do material ensilado in natura $(50 \mathrm{~g}$ ) foi triturada com $200 \mathrm{~mL}$ de água, em liquidificador industrial, e filtrada em gaze para extração do meio aquoso, que foi utilizado imediatamente para análise de nitrogênio amoniacal $\left(\mathrm{N}-\mathrm{NH}_{3}\right)$ e $\mathrm{pH}$. O teor de N-NH , como porcentagem do NT, foi dosado imediatamente utilizando-se óxido de magnésio e cloreto de cálcio, segundo Cunniff (1995), ao passo que os teores dos ácidos lático, acético e butírico foram quantificados em cromatógrafo a gás, segundo metodologia descrita por Wilson (1971), com modificações de Boin (1975).

\begin{tabular}{|c|c|c|}
\hline Item & $\begin{array}{l}\text { Capim-elefante } \\
\text { Elephantgrass }\end{array}$ & $\begin{array}{l}\text { Casca de café } \\
\text { Coffee hulls }\end{array}$ \\
\hline MS & 17,2 & 90,6 \\
\hline $\begin{array}{l}D M \\
\mathrm{~PB}\end{array}$ & 8,7 & 9,8 \\
\hline$C P$ & & \\
\hline $\begin{array}{l}\mathrm{FDN}^{1} \\
N D F\end{array}$ & 71,3 & 69,3 \\
\hline $\begin{array}{l}\mathrm{FDA}^{1} \\
A D F\end{array}$ & 48,2 & 51,7 \\
\hline Hemicelulose ${ }^{1}$ & 23,0 & 17,5 \\
\hline Celulose $\mathrm{e}^{1}$ & 42,0 & 34,3 \\
\hline $\begin{array}{l}\text { Cellulose } \\
\text { Lignina }^{1} \\
\text { Lignin }\end{array}$ & 5,6 & 16,1 \\
\hline $\begin{array}{l}\text { Nitrogênio insolúvel } \\
\text { em detergente ácido }{ }^{2} \\
\text { Acid detergent insoluble } \\
\text { nitrogen }^{2}\end{array}$ & 9,5 & 40,5 \\
\hline $\begin{array}{l}\text { Carboidratos solúveis }{ }^{1} \\
\text { Soluble carbohydrates }\end{array}$ & 14,6 & 22,2 \\
\hline $\begin{array}{l}\text { Digestibilidade in vitro da } \mathrm{MS}^{1} \\
\text { In vitro } D M \text { digestibility }\end{array}$ & 61,1 & 51,1 \\
\hline
\end{tabular}


Os resultados foram interpretados por meio de análises de variância e regressão, utilizando o programa SAEG Sistema para Análises Estatísticas (Ribeiro Jr., 2001).

\section{Resultados e Discussão}

A adição dos níveis de casca de café promoveu acréscimo linear no teor de MS das silagens (Tabela 2), estimado em $0,77 \%$ por unidade de casca adicionada. Estimado pela equação de regressão, o nível de casca de café adicionada à ensilagem de capim-elefante com $17 \%$ de MS para se obter silagem com $30 \%$ de MS é de $18,9 \%$.

Incremento nos teores de MS em silagens também foi observado por Carvalho (2006), que adicionaram níveis de $0,7,14,21$ e $28 \%$ de farelo de cacau à ensilagem de capimelefante. Esse autor verificou acréscimo de $0,74 \%$ no teor de MS por unidade de farelo de cacau adicionada, próximo aos $0,77 \%$ observados neste trabalho (Tabela 2). Esse aumento provavelmente ocorreu em razão de o teor de MS da casca de café (91\%) ser semelhante ao do farelo de cacau (90\%). Além disso, o capim-elefante utilizado neste experimento apresentou teor de MS (17,2\%) próximo ao observado $(20,3 \%)$ no capim utilizado pelo autor.

$\mathrm{O}$ teor de PB da silagem comportou-se de maneira quadrática em função dos níveis de casca de café e, para atingir seu máximo valor $(9,9 \%)$, o nível de casca de café deve ser de 16,3\% (Tabela 2).

Os teores de PB das silagens com casca de café mantiveram-se próximos do teor de PB do capim-elefante antes da ensilagem, entretanto, observou-se menor teor desta fração na silagem sem casca de café. A perda de PB observada na silagem sem casca de café, em parte, poder ser atribuída à produção de efluente, que acumulou na extremidade do silo, promovendo desenvolvimento de bolores e de um material com característica e odor desagradável. Ainda nesta silagem produzida sem casca de café, notadamente ocorreu desenvolvimento de bactérias do gênero Clostridium, em decorrência do excesso de umidade do capim. O desenvolvimento dessas bactérias levou a fermentações secundárias indesejáveis, havendo maior formação de ácido butírico (Figura 4). McDonald et al. (1991) destacaram que, concomitantemente à formação de ácido butírico, ocorre degradação de proteína e ácido lático, explicando, dessa forma, os menores teores de PB na silagem sem casca de café.

Resultados semelhantes foram observados por Bernardino et al. (2005), que, avaliando a adição de casca de café na ensilagem de capim-elefante contendo $12 \%$ de MS, também observaram perda de PB na silagem produzida sem adição de casca de café.
$\mathrm{O}$ teor de FDN das silagens reduziu linearmente em função dos níveis de casca de café, em virtude do efeito de adição de casca, pois o teor de FDN da casca de café foi três unidades percentuais inferior ao do capim-elefante no momento na ensilagem. Observou-se redução de $0,18 \%$ no teor de FDN por unidade de casca de café adicionada.

Souza et al. (2003), avaliando a casca de café na ensilagem de capim-elefante, observaram maior percentual $(0,31 \%)$ de redução no teor de FDN por unidade de casca de café adicionada. $\mathrm{O}$ menor percentual verificado neste trabalho se deve ao maior teor de FDN da casca de café $(69,3 \%)$, uma vez que a casca utilizada neste experimento apresentou 16,6 unidades percentuais superiores ao da utilizada por esses autores.

Semelhantemente ao resultado obtido nesta pesquisa, Carvalho (2006) também verificou redução no teor de FDN de silagens acrescidas com material absorvente de umidade. Esse autor relatou teores de FDN de 76,5; 71,4; 66,$3 ; 63,9$ e $61,9 \%$, respectivamente, para os níveis de 0 , $7,14,21$ e $28 \%$ de adição (peso/peso) de farelo de cacau.

Foi observado efeito linear crescente sobre o teor de FDA, verificando-se acréscimo de $0,12 \%$ no teor de FDA por unidade de casca adicionada. A casca de café apresentou teor de FDA 7,26\% superior ao capim-elefante, explicando a elevação desta fração em função dos níveis de casca adicionados.

A menor digestibilidade de alimentos em animais ruminantes tem sido freqüentemente correlacionada ao teor de FDA; assim, em um eventual sistema de alimentação, esses acréscimos verificados nas silagens com adição de casca de café devem ser considerados, pois menores teores de NDT podem ser obtidos na dieta total e reduzir o desempenho dos animais.

Os valores observados para os teores de FDA neste experimento foram superiores aos relatados por Souza et al. (2003), que verificaram teores de 46,6; 42,3; 42,5; 41,8 e $44,1 \%$, respectivamente, para os níveis de $0 ; 8,7 ; 17,4 ; 26,1$ e $34,8 \%$ de adição de casca de café. De maneira geral, os valores encontrados foram altos e reduziram o valor nutritivo das silagens.

Os níveis de casca de café adicionados na ensilagem não afetaram o teor de celulose das silagens, verificando-se teor médio de $42,8 \%$, resultado que corrobora os encontrados por Bernardino et al. (2005), que também não verificaram significância para o teor de celulose, em função de diferentes níveis de casca de café. Por outro lado, neste estudo, os teores de lignina aumentaram linearmente em função dos níveis de casca de café, o que pode ser atribuído ao maior teor de lignina da casca $(16,1 \%)$ adicionada durante a ensilagem em comparação ao do capim-elefante $(5,6 \%)$. 
Tabela 2 - Composição química e digestibilidade in vitro da MS (DIVMS) de silagens de capim-elefante, em função dos níveis crescente de adição de casca de café

Table 2 - Chemical composition and in vitro DM digestibility (IVDMD) of elephantgrass silages with different coffee hull levels

\begin{tabular}{|c|c|c|c|c|c|c|c|c|c|c|}
\hline \multirow[t]{2}{*}{ Item } & \multicolumn{5}{|c|}{$\begin{array}{l}\text { Casca de café }(\%) \\
\text { Coffee hulls }(\%)\end{array}$} & \multirow[b]{2}{*}{$\mathrm{CV}(\%)$} & \multicolumn{2}{|c|}{$\mathrm{P}$} & \multirow[b]{2}{*}{$\begin{array}{l}\text { Equação de regressão } \\
\text { Regression equation }\end{array}$} & \multirow[b]{2}{*}{$\mathrm{R}^{2}$} \\
\hline & 0 & 6 & 12 & 18 & 24 & & $\mathrm{~L}$ & Q & & \\
\hline MS (DM) & 15,2 & 19,9 & 24,8 & 29,5 & 33,7 & 5,8 & 0,0001 & NS & $\hat{\mathrm{y}}=15,3095+0,777083 \mathrm{X}$ & 1,00 \\
\hline $\mathrm{PB}^{1}(C P)$ & 6,7 & 9,0 & 9,5 & 9,8 & 9,3 & 6,8 & 0,0001 & 0,0001 & $\hat{y}=6,85071+0,373220 X-0,0114137 X^{2}$ & 1,00 \\
\hline $\mathrm{FDA}^{1}(A D F)$ & 48,6 & 48,9 & 49,7 & 50,6 & 51,4 & 3,0 & 0,0079 & NS & $\hat{y}=48,3805+0,121417 X$ & 0,98 \\
\hline $\mathrm{CEL}^{1}$ & 42,6 & 43,1 & 43,3 & 42,6 & 42,2 & 9,3 & NS & NS & $\hat{\mathrm{y}}=\mathrm{y}=42,8$ & - \\
\hline $\mathrm{LIG}^{1}$ & 5,6 & 5,8 & 6,6 & 7,9 & 9,0 & 10,4 & 0,0001 & 0,1042 & $\hat{y}=5,16450+0,150167 X$ & 0,94 \\
\hline $\mathrm{NIDA}^{2}(A D I N)$ & 9,6 & 11,4 & 13,3 & 15,1 & 17,9 & 11,4 & 0,0001 & NS & $\hat{y}=9,38050+0,338792 x$ & 0,99 \\
\hline
\end{tabular}

$1 \%$ da MS (DM \%); 2 \% do nitrogênio total (total nitrogen \%); CV = coeficiente de variação (coefficient of variation); $L=$ linear (linear); $Q=$ quadrático (quadratic). $\mathrm{MS}=$ matéria seca; $\mathrm{PB}=$ proteína bruta; FDN = fibra em detergente neutro; FDA = fibra em detergente ácido; CEL = celulose; LIG = lignina; NIDA = nitrogênio insolúvel em detergente ácido, DIVMS = digestibilidade in vitro da MS.

$D M=$ dry matter $C P=$ crude protein; $N D F=$ neutral detergent fiber; $A D F=$ and acid detergent fiber; $C E L=$ cellulose, $L I G=$ lignin; $A D I N=$ acid detergent insoluble nitrogen; $I V D M D=$ in vitro DM digestibility.

Estimou-se que, para cada unidade de casca de café adicionada, o acréscimo no teor de lignina da silagem foi de $0,15 \%$

O teor de NIDA das silagens aumentou com a inclusão dos níveis de casca de café na ensilagem. De acordo com McDonald et al. (1991), o aquecimento da massa ensilada, por ocasião da fermentação no interior do silo, contribui para elevação dos teores de NIDA. Contudo, os elevados teores de NIDA nas silagens podem ser explicados pelos maiores valores deste componente na casca de café em relação ao capim-elefante no momento da ensilagem (Tabela 1).

O NIDA, que corresponde às proteínas associadas à lignina, complexos tanino-proteína e produtos oriundos da reação de Maillard, é altamente resistente às enzimas microbianas e indigestível ao longo do trato gastrintestinal (Licitra et al., 1996). Em um sistema de alimentação de ruminantes, o fornecimento de um alimento com elevado teor de NIDA afetará o atendimento dos requisitos de nitrogênio dos microrganismos ruminais (Van Soest, 1994), assim, fica implícito que alimentos com teores de PB similares, mas com diferenças nos teores de NIDA, resultarão em predições incorretas sobre o desempenho animal. Deste modo, do ponto de vista nutricional, elevação nos teores de NIDA não é desejável.

A adição de casca de café na ensilagem afetou significativamente a DIVMS, verificando-se redução linear, que pode ser explicada pelo elevado teor de lignina na casca de café, $187,5 \%$ superior ao do capim-elefante. Os valores estimados de DIVMS foram de 60,8;58,2; 55,5; 52,8 e 50,2\%, respectivamente, para os níveis de $0,6,12,18$ e $24 \%$ de casca de café. A redução observada na digestibilidade indica menor aproveitamento dos nutrientes pelos microrganismos ruminais, com conseqüente menor disponibilidade de energia e proteína ao sistema ruminal. O maior teor de NIDA e lignina nas silagens com casca de café, provavelmente, foram os itens que contribuíram para a menor digestibilidade, visto que este último é um composto fenólico e tem correlação negativa com a digestibilidade.

Os resultados obtidos nesta pesquisa corroboram os encontrados por Bernardino et al. (2005), que estudaram a adição de níveis de casca de café $(0,10,20,30$ e $40 \%)$ no capim-elefante e observaram redução linear na DIVMS. Do mesmo modo, Souza et al. (2003) também avaliaram o capimelefante acrescido de casca de café $(0 ; 8,7 ; 17,4 ; 26,1$ e $34,7 \%$ ) na produção de silagem e registraram decréscimo linear na DIVMS.

Os teores de $\mathrm{N}-\mathrm{NH}_{3}$ comportaram-se de forma quadrática em função dos níveis de casca de café, estimando-se valor mínimo de 7,4\% de $\mathrm{N}-\mathrm{NH}_{3}$ (\% do N-total) para o nível de 18,7\% de adição de casca (Figura 1). McDonald et al. (1991) sugeriram que silagens para serem consideradas de boa qualidade devem apresentar teor de $\mathrm{N}-\mathrm{NH}_{3}$ (\% N-total) de, no máximo, $10 \%$. Nas condições em que o experimento foi realizado, considerando-se o teor de MS do capim-elefante e a composição da casca de café (Tabela 1), estimada pela equação (Figura 1), a adição de níveis de casca de café entre 8 e 29,5\% produz silagens com teor de $\mathrm{N}-\mathrm{NH}_{3}$ dentro da faixa recomendada por McDonald et al. (1991). 


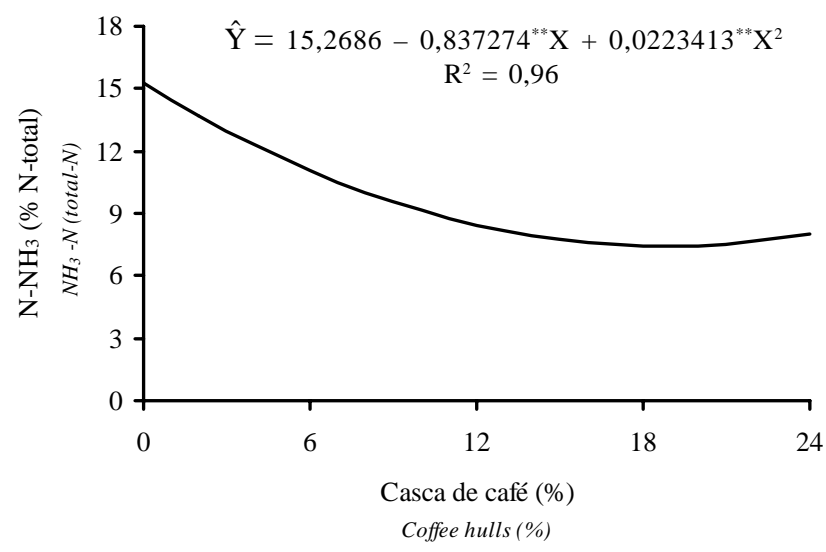

Figura 1 - Estimativa dos teores de nitrogênio amoniacal $\left(\mathrm{N}-\mathrm{NH}_{3}\right)$ das silagens, em função de diferentes níveis de casca de café. ${ }^{* *} \mathrm{P}<0,01$ pelo teste $\mathrm{F}$.

Figure 1 - Estimate of ammonia nitrogen $\left(\mathrm{NH}_{3}-\mathrm{N}\right)$ concentration of silages as a function of different levels of coffee hulls. ${ }^{*} P<0.01$ by F test.

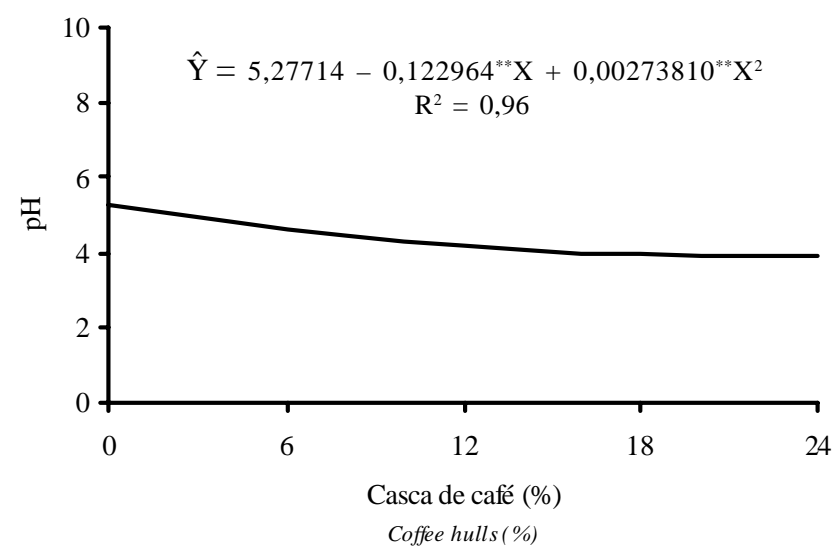

Figura 2 - Valores de pH das silagens, em função de diferentes níveis de casca de café. ${ }^{* *} \mathrm{P}<0,01$ pelo teste $\mathrm{F}$.

Figure 2 - $\quad p H$ values of silages as a function of different levels of coffee hulls. ${ }^{* *} P<0.01$ by $F$ test.

Após a colheita do capim-elefante, ocorre rápida proteólise, que cessa somente quando $\mathrm{pH}$ é reduzido a 4,0 ou 4,5 (Vilela, 1990), mas varia em extensão, dependendo da espécie ensilada, do teor de MS e da temperatura. Assim, maiores teores de $\mathrm{N}-\mathrm{NH}_{3}$ em silagens, muitas vezes, estão associados ao maior teor de PB do material inicial, o que pode explicar a elevação dos teores de $\mathrm{N}-\mathrm{NH}_{3}$ a partir do nível de adição de $18,7 \%$ de casca de café. Semelhantemente ao resultado obtido neste experimento, Zanine et al. (2006) verificaram maiores teores de $\mathrm{N}-\mathrm{NH}_{3}$ para silagens produzidas com material inicial contendo maior teor de PB, uma vez que o farelo de trigo utilizado na ensilagem pelos autores foi o responsável pela elevação da PB. De qualquer forma, mesmo em silagens bem preservadas, o teor de proteína verdadeira é reduzido para 50 a $60 \%$ do total de compostos nitrogenados (McDonald et al., 1991).

Os valores de $\mathrm{pH}$ em função dos níveis de casca de café comportaram-se de maneira quadrática (Figura 2), estimando-se valor mínimo de 3,8 para o nível de 22,5\% de casca de café. Entre os tratamentos estudados, as silagens de capimelefante com 12, 18 e $24 \%$ de casca de café apresentaram valor de $\mathrm{pH}$ dentro da faixa considerada como ótima (3,8 a 4,2) para fermentação adequada (McDonald et al., 1991).

Alto $\mathrm{pH}$ é indicativo de maior produção dos ácidos acético e butírico, característicos dos processos de fermentação indesejável (Van Soest, 1994). Tudo indica que os maiores teores de carboidratos solúveis verificados na casca de café (Tabela 1) contribuíram para o rápido abaixamento do $\mathrm{pH}$, o que favoreceu a produção de ácido lático (Figura 3).

No tocante aos teores de ácido lático, verificou-se comportamento quadrático (Figura 3), estimando-se valor máximo de $11,4 \%$ para a adição de $25,6 \%$ de casca de café na ensilagem.

Rodrigues et al. (2005) e Carvalho (2006), trabalhando, respectivamente, com polpa cítrica e farelo de cacau adicionado na ensilagem de capim-elefante, verificaram valor médio de ácido lático de $4 \%$ em silagens aditivadas com esses subprodutos. Os teores observados em todos os tratamentos avaliados neste experimento foram superiores aos verificados pelos demais autores. O estádio de maturidade e o tipo de material a ser ensilado, associados ao teor de MS e à presença de carboidratos solúveis, são alguns fatores que determinam à extensão da fermentação no interior do silo e a quantidade de ácido lático na silagem. Portando, essas variações observadas entre os teores de ácido lático dos experimentos realizados com forrageiras tropicais podem ser consideradas normais.

Com a elevação do teor de ácido lático observado nos tratamentos em função dos níveis de adição de casca de café, fica evidenciado que a casca de café pode ser utilizada na ensilagem, melhorando a preservação do material.

Os teores de ácido acético não apresentaram significância mediante a adição dos níveis de casca de café na ensilagem (Figura 4), verificando-se valor médio de $0,7 \%$ para as silagens. Este teor de ácido acético se encontra abaixo do nível crítico de $0,8 \%$ (Muck, 1988), sugerindo boa preservação da massa ensilada, posto que teores superiores indicam alterações indesejáveis ocorridas durante a fermentação.

O comportamento quadrático verificado para os teores de ácido butírico (Figura 4), estimando-se valor mínimo de $0,11 \%$ para o nível de $23,4 \%$ de casca, ratifica a boa preservação do material ensilado. 
A literatura revela certa variação entre as concentrações dos ácidos orgânicos nas silagens de capim-elefante com ou sem uso de aditivos (Ferrari Jr. \& Lavezzo 2001; Andrade \& Melotti, 2004; Carvalho, 2006). Entre outros fatores, esta variação pode ser atribuída ao material utilizado, à umidade da forragem no momento da ensilagem e ao teor de carboidratos solúveis.

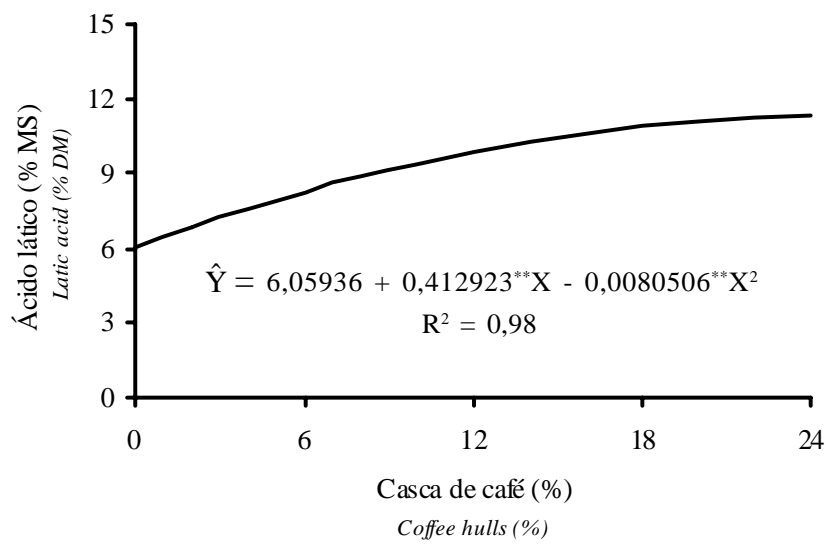

Figura 3 - Estimativa dos teores de ácido lático (\% MS) das silagens, em função de diferentes níveis de casca de café. $^{* *} \mathrm{P}<0,01$ pelo teste $\mathrm{F}$.

Figure 3 - Estimate of lactic acid (\% DM) concentration of silages as a function of different levels of coffee hulls. ${ }^{* *} P<0.01$ by $F$ test.

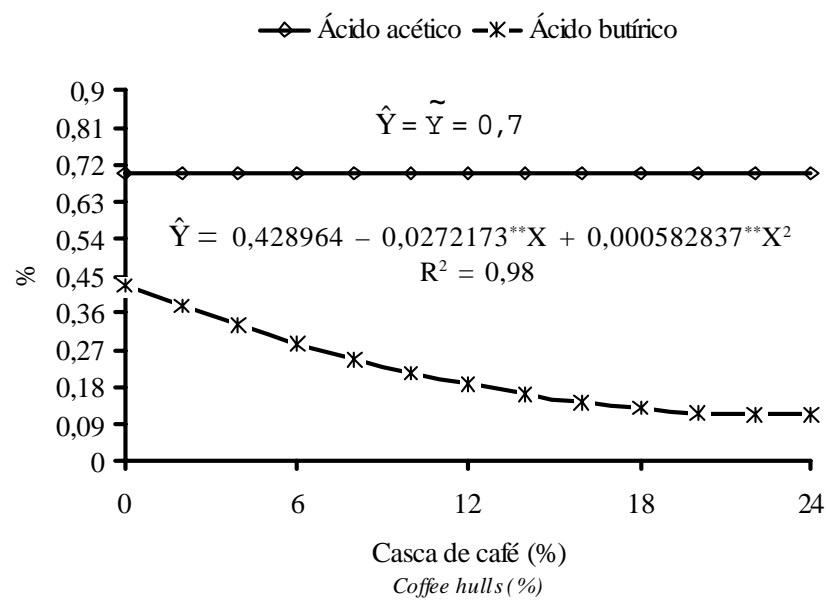

Figura 4 - Estimativa dos teores de ácidos acético e butírico (\% MS) das silagens, em função de diferentes níveis de casca de café. ${ }^{* *} P<0,01$ pelo teste $F$.

Figure 4 - Estimate of acetic and butyric acid (\% DM) concentration of silages as function of different levels of coffee hulls. ${ }^{* *} P<0.0$ by $F$ test.

\section{Conclusões}

A adição de casca de café na ensilagem de capimelefante contendo $17 \%$ de MS foi eficiente em reduzir o teor de umidade da silagem; entretanto, a digestibilidade in vitro da MS das silagens diminuiu.

A casca de café utilizada na ensilagem de capim-elefante melhora as características fermentativas da silagem, diminuindo os valores de $\mathrm{pH}$ e os teores de nitrogênio amoniacal e de ácido butírico e aumentando os teores de ácido lático, promovendo, desta forma, melhor conservação do material ensilado.

\section{Literatura Citada}

ANDRADE, S.J.T.; MELOTTI, L. Efeito de alguns tratamentos sobre a qualidade da silagem de capim-elefante cultivar Napier (Pennisetum purpureum, Schum.). Brazilian Journal of Veterinary Research and Animal Science, v.41, n.6, p.409415,2004

BERNARDINO, F.S.; GARCIA, R.; ROCHA, F.C. et al. Produção e características do efluente e composição bromatológica da silagem de capim-elefante contendo diferentes níveis de casca de café. Revista Brasileira de Zootecnia, v.34, n.6, p.21852291, 2005.

BOIN, C. Elephant (Napier) grass silage production, effect of addition on chemical composition, nutritive value and animal performances. Ithaca: Cornell University, 1975. 215p. Thesis (Doctor in Animal Nutrition) - Cornell University, 1975.

CARVALHO, G.G.P. Capim-elefante emurchecido ou com farelo de cacau na produção de silagem. Viçosa, MG: Universidade Federal de Viçosa, 2006. 69p. Dissertação (Mestrado em Zootecnia) - Universidade Federal de Viçosa, 2006.

CUNNIFF, P. Official methods of analysis of AOAC International. 16.ed. Arlington: AOAC International, 1995. v. 1 .

EVANGELISTA, A.R.; PERON, A.J.; AMARAL, P.N.C. Forrageiras não convencionais para silagem - Mitos e realidades. In: SIMPÓSIO SOBRE MANEJO ESTRATÉGICO DA PASTAGEM, 2., 2004, Viçosa, MG. Anais... Viçosa, MG: Universidade Federal de Viçosa, 2004. p.463-507.

FERRARI JR., E.; LAVEZZO, W. Qualidade da silagem de capimelefante (Pennisetum purpureum, Schum) emurchecido ou acrescido e de farelo de mandioca. Revista Brasileira de Zootecnia, v.30, n.5, p.1424-1431, 2001.

LICITRA, G.; HERNANDEZ, T.M.; van SOEST, P.J. Standardization of procedures for nitrogen fractionation of ruminant feeds. Animal Feed Science and Technology, v.57, n.4, p.347-358, 1996.

McDONALD, P.; HENDERSON, A.R.; HERON, S.J.E. The biochemistry of silage. 2.ed. Marlow: Chalcombe Publications, 1991. 340p.

MUCK, R.E. Factors influencing silage quality and their implications for management. Journal of Dairy Science, v.71, n.11, p.2992-3002, 1988.

RIBEIRO JR., J.I. Análises estatísticas no SAEG (Sistema para análises estatísticas). Viçosa, MG: Universidade Federal de Viçosa, 2001. 301p.

RODRIGUES, P.H.M.; BORGATTI, L.M.O.; GOMES, R.W. et al. Efeito da adição de níveis crescentes de polpa cítrica sobre a qualidade fermentativa e o valor nutritivo da silagem de capim- 
elefante. Revista Brasileira de Zootecnia, v.34, n.4, p.1138$1145,2005$.

SILVA, D.J.; QUEIROZ, A.C. Análise de alimentos: métodos químicos e biológicos. Viçosa, MG: Universidade Federal de Viçosa, 2002. 235p.

SOUZA, A.L.; BERNARDINO, F.S.; GARCIA, R. et al. Valor nutritivo da silagem de capim-elefante (Pennisetum purpureum, Schum.) com diferentes níveis de casca de café. Revista Brasileira de Zootecnia, v.32, n.4, p.828-833, 2003.

Van SOEST, P.J. Nutritional ecology of the ruminant. 2.ed. Ithaca: Cornell University Press, 1994. 476p.
VILELA, D. Utilização do capim-elefante na forma de forragem conservada. In: SIMPÓSIO SOBRE CAPIM-ELEFANTE, 1990, Coronel Pacheco. Anais... Coronel Pacheco: EMBRAPA Centro Nacional de Pesquisa de Gado de Leite, 1990. p.89-131.

ZANINE, A.M.; SANTOS, E.M.; FERREIRA, D.J. et al. Avaliação da silagem de capim-elefante com adição de farelo de trigo. Archivos de Zootecnia, v.55, n.209, p.75-84, 2006.

Recebido: 12/6/2006 Aprovado: 1/6/2007 